\title{
Polymorphic ventricular tachycardia on a young patient
}

\author{
Osman Can Yontar ${ }^{1}$, Erhan Tenekecioglu' ${ }^{1}$, Kemal Karaagac ${ }^{1}$, Ahmet Tutuncu ${ }^{1}$ \\ ${ }^{1}$ Department of Cardiology, Bursa Postdoctorate Training and Research Hospital, Bursa, Turkey
}

\section{A B S T R A C T}

Twelve-lead electrocardiogram is the most frequently utilized device for cardiologists. Although it is a basic device, great attention must be paid when it comes to give vital decisions.

Key words: Ventricular tachycardia, parasite, electrocardiogram
Access this article online

Website:

http://nepjol.info/index.php/AJMS

\section{INTRODUCTION}

This is an electrocardiogram of a patient who admitted to emergency room with complaint of dyspnoea.

\section{CASE REPORT}

A twenty nine-year-old female patient admitted to emergency room. Patient had complaint of sudden onset dyspnoea and palpitation. Patient's physical examination except mildly increased heart rate (100-110 beats/minute) and hyperventilation without rales, and blood pressure was $110 / 70 \mathrm{mmHg}$. At first sight, patient appeared to be hysterical or in a type of panic attack. While her physician was asking about her medical history, she looked pale and nervous and began sweating. Patient's abrupt distortion drove doctors to see if there was something wrong about her rhythm. It was a typically crowded night for emergency room and all the monitors were occupied. Physicians decided to monitor her with an available defibrillator in the initial exam booth, instead of waiting for a monitored bed, just in case of missing a serious rhythm problem. Figure 1 is the rhythm strip obtained from the defibrillator monitor. The strip showed a polymorphic ventricular tachycardia and that was unexpected. Due to patient's stable hemodynamic status, physicians avoided DC shock and obtained a 12-lead electrocardiography urgently. Figure 2 shows eleven leads extremely resembling a polymorphic ventricular tachycardia and only one lead (D1) displaying the true rhythm which was normal sinus.

\section{DISCUSSION}

Electrocardiographic artifact is a common problem which is recognized easily in most cases. Often caused by patient movement (voluntary or involuntary), other sources should be considered, such as 60 cycle-persecond interference from nearby sources of alternating current and electrode and cable problems $(1,2)$. In this case it seems that there was an interfering source because the artifact existed in both recorders. Characteristics that differentiate artifact from ventricular tachycardia include the absence of hemodynamic collapse during the event; visible normal QRS complexes within the artifact; an unstable base line on the electrocardiogram before

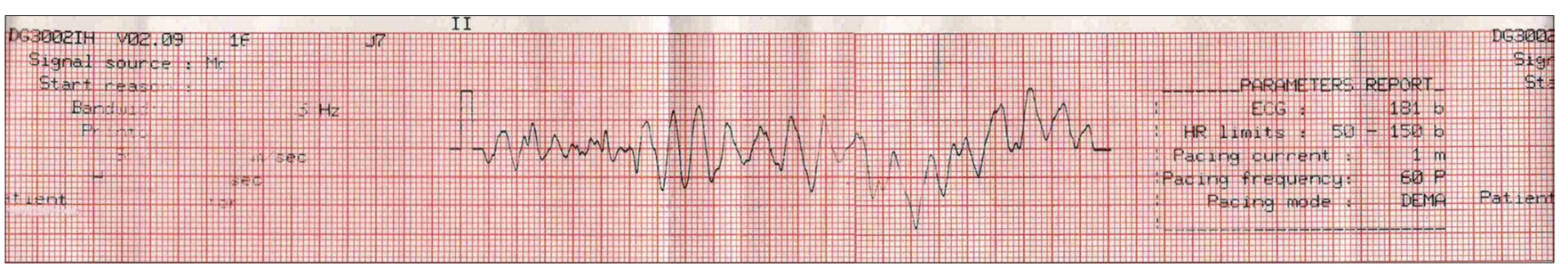

Figure 1: Single derivation rhythm strip resembling polymorphic ventricular tachycardia 




Figure 2: Simultaneous 12 lead electrocardiogram, arrows show underlying true QRS complexes the event, after the event, or both; and an association with body movement (3). In figure 2 , arrows indicate the QRS complexes marching through in V6 with rate of 78 beats/minute. Unexpected arrhythmias detected on a monitor displaying only one lead should alert physicians to obtain a 12-lead electrocardiogram before giving vital decisions.

\section{REFERENCES}

1. Surawica B. Assessing abnormal ECG patterns in the absence of heart disease. Cardiovasc Med 1977;2:629.

2. Chase $\mathrm{C}$ and Brady WJ. Artifactual electrocardiographic change mimicking clinical abnormality on the ECG. Am J Emerg Med 2000;18:312.

3. Lin SL, Wang SP, Kong CW and Chang MS. Artifact simulating ventricular and atrial arrhythmia. Jpn Heart J 1991;32:847-51.

Authors Contribution:

OCY - Writing, finder of case patient; ET - Writing, English translation; KK - Supervision, correction; AT - Finder of case, english translation

Source of Support: Nil, Conflict of Interest: None declared. 